\title{
EFFECT OF MUSIC ON PHYSIOLOGICAL PARAMETERS AND ANXIETY IN PATIENTS WITH CHRONIC OBSTRUCTIVE PULMONARY DISEASE
}

\section{Deshmukh Aboli Vivekrao ${ }^{1}$, Nagarwala Raziya*2,Shyam Ashok ${ }^{3}$,Sancheti Parag ${ }^{4}$}

${ }^{1}$ BPTh. Sancheti Institute College of Physiotherapy, Pune,

${ }^{* 2}$ MPTh in Cardio-Respiratory Sciences, Professor, Department of Cardio-Respiratory Sciences, Sancheti Institute College of Physiotherapy, Pune.

${ }^{3}$ MS Ortho, Research Officer, Sancheti Institute of Orthopedics and Rehabilitation, Pune.

${ }^{4} \mathrm{MS}$ Ortho, Chairman, Sancheti Institute for Orthopedics and Rehabilitation, Pune.

\section{ABSTRACT}

Background: Respiratory Condition is an umbrella term. It includes many respiratory diseases, amongst which COPD is a leading cause of distress. Hospitalized Patients with COPD often suffer from anxiety due to many underlined causes. Anxiety is an unpleasurable emotional state; it goes hand in hand with COPD condition. Effect of music on anxiety reduction and physiological parameters is culturally known but lacks much attention in treatment settings. So the purpose of this study is to find out the effect of music on physiological parameters and anxiety in COPD patients.

Materials and Methods: In this Experimental type of study, carried out in tertiary care hospitals in Pune city, 42 patients were selected by purposive sampling technique as per inclusion criteria, both male and females with COPD and MMRC dyspnoea grade 2 and 3. Pre intervention physiological parameters i.e. Respiratory rate, Heart rate, Blood pressure along with anxiety score using State Trait Anxiety Inventory Scale were checked and noted. After the Music intervention of 15-20 minutes all the outcome measures were checked again and noted. Data collected was analyzed using Paired t-test and Wilcoxon method.

Result and Conclusion: P values for RR, PR, SBP, DBP and STAI are $0.00,0.00,0.012,0.001$ and 0.00 respectively which are $(<0.05)$ statistically significant. Mean values of RR, PR and STAI have shown significant change, pre and post intervention; whereas mean BP stayed the same. So the study concludes that music has significant effect on physiological parameters and anxiety, and it can be incorporated as a non pharmacological intervention in clinical settings.

KEY WORD: COPD, Music, Anxiety, Respiratory Rate, Pulse Rate, Blood pressure.

Address for correspondence: : Dr. Nagarwala Raziya, MPTh in Cardio-Respiratory Sciences, Professor, Department of Cardio-Respiratory Sciences, Sancheti Institute College of Physiotherapy, Sancheti Healthcare academy, Thube Park, Shivajinagar, Pune -411005, Telephone: +91-9850816350, Fax: +91 2025539494 E-Mail: rnagarwala@gmail.com

Access this Article online

Quick Response code

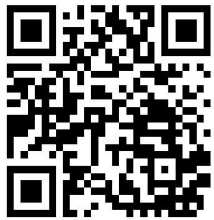

DOI: $10.16965 /$ ijpr.2017.152
Journal Information

International Journal of Physiotherapy and Research

ICV for 2016 ISSN (E) 2321-1822 | ISSN (P) 2321-8975

https://www.ijmhr.org/ijpr.html

DOI-Prefix: https://dx.doi.org/10.16965/ijpr

\section{Article Information}

Received: 04 Apr 2017

Peer Review: 04 Apr 2017

Revised: 18 Aug 2017
Accepted: 18 Aug 2017

Published (O): 11 Feb 2018

Published (P): 11 Feb 2018

\section{INTRODUCTION}

Respiratory condition is an umbrella term which includes many diseases, amongst which COPD is a leading cause of distress. Worldwide in 2001
COPD was $5^{\text {th }}$ most common cause of death, responsible for $4.7 \%$ of deaths and $2 \%$ of disability adjusted life years (DALYs) [1]. A 30 year projection from 1990 predicted a steady rise 
in number of COPD deaths to $3^{\text {rd }}$ most common cause by 2020 [2]. In South Africa respiratory disease as a group (excluding TB) was ranked as the $7^{\text {th }}$ most important cause of DALYs (4.7\%) in 2000 [3].

Inspite of medications, Hospitalized patients with COPD often suffer from anxiety due to many underlined causes like uncertainty regarding surroundings or progression of symptoms, isolation from family etc. Dyspnoea is a major concern; it is a condition when patient becomes painfully aware to breathe more. They tend to hyperventilate causing short of breath and air hunger is produced. In respiratory pathology, diaphragm is mainly affected because of underlined obstructive as well as restrictive condition; which restricts respiration resulting in shallow breathing. Shallow breathing increases work of breathing and it costs accessory muscles of ventilation to work more. More energy expenditure associated with state of hypoxia due to metabolic alterations causes generalized weakness and distress. So the patient is not completely relaxed and becomes more distress and anxious. In this way Anxiety goes hand in hand with respiratory condition [4].

Anxiety is "An unpleasurable emotional state, associated with psycho-physiological changes in response to an intra-psychic conflict"[5]. Anxiety is a state of apprehension and it becomes pathological when it causes significant subjective distress or impairment in normal individual as well. Anxiety is significant co-morbid and potentially modifiable factor in patients with COPD. Many non-pharmacological interventions are studied to reduce anxiety. According to Munro and Mount (1978),"Music therapy is the controlled use of music and its influence on the human being to aid in physiological, psychological and emotional integration of the individual during treatment of an illness or disability." Significant reduction in physiological parameters was observed in asymptomatic individuals immediately after listening to the music [6].

Suhartini studied and proved the Power of music in hospital wards to aid in the healing process of soldiers injured in the war [7].

Effect of music is culturally known, despite this, music has not given much attention in medical Int J Physiother Res 2018;6(1):2573-76. I ISSN 2321-1822 settings. So it becomes an area of concern to study if non-pharmacological music therapy can be used as a supportive treatment in COPD patients.

\section{MATERIALS AND METHODS}

After approval from the ethical committee of the Institutes, this experimental type of study was done in tertiary care hospitals of Pune city. Where 42 patients both male and females with COPD and MMRC dyspnoea grade 2 and 3 were included by purposive sampling technique. Patients on sedatives or anti anxiety, unconscious, psychologically disturbed and having major hearing problems were excluded from the study.

Written informed consent form was taken from them.

Baseline parameters for RR, PR, BP and STAI [8, 9] score was checked and noted. 15-20 min [10] of soothing instrumental music intervention of 60-90 beats per minutes was given through headphones. Post intervention again RR, PR, BP and STAI was checked and noted. Data collected was analyzed using appropriate statistical tests.

\section{RESULTS}

Paired-t test was used for the pre and post intervention for analysis of parametric data of respiratory rate, pulse rate, systolic and diastolic blood pressure. $P$ value for which are 0.00 , $0.00,0.001$ and 0.012 respectively; which is significant as it is less than set $p$ value of 0.05 .

Wilcoxon test was used for pre and post intervention for non-parametric data of STAI score $P$ was 0.00 which suggests that it is significant and less than set $p$ value of 0.05 .

Table 1 and Graph 1 shows statistical values for mean, standard deviation and $p$-value of pre and post intervention values of RR, PR, BP and STAI.

Table 1: Pre \& Post values for mean standard deviation and $p$ value.

\begin{tabular}{|l|c|c|c|}
\hline & pre & post & P-value \\
\hline Pulse rate & $106.19 \pm 10.19$ & $99.42 \pm 8.81$ & 0 \\
\hline Systolic BP & $128.15 \pm 7.24$ & $126.61 \pm 5.19$ & 0.001 \\
\hline Diastolic BP & $82.57 \pm 5.39$ & $82.00 \pm 4.89$ & 0.012 \\
\hline Respiratory rate & $36.19 \pm 4.58$ & $29.61 \pm 3.64$ & 0 \\
\hline STAl score & $59.13 \pm 7.72$ & $40.81 \pm 8.53$ & 0 \\
\hline
\end{tabular}


Graph 1: comparison of pre and post intervention values of RR, PR, SBP, DBP and Anxiety STAI score.

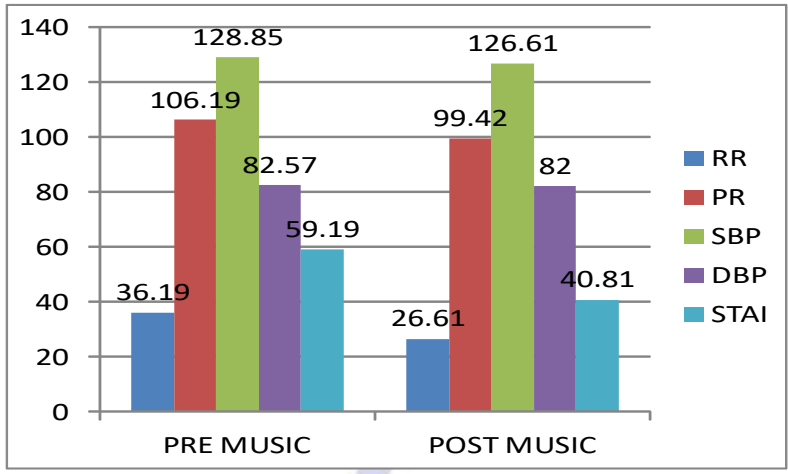

\section{DISCUSSION}

The ultimate goal of any study is to enhance patient's comfort as compared to baseline condition at the time of admission and prevent associated secondary complications. Aim of this study was to find out effect of music on physiological parameters and anxiety in patients with COPD.

Anxiety and Breathlessness becomes major concern in hospitalized respiratory patients [4]. Many alternatives like breathing exercises, music, muscle relaxation techniques [11] etc. are known as a non pharmacological ways to reduce anxiety.

Suhartini in 2009 studied and proved the Power of music in hospital wards to aid in the healing process of soldiers injured in the war [6].

Study done by Nilsson $U$, Unosson $M$ and Rawal N. proved that, music therapy may reduce Anxiety, pain and morphine consumption on patients having open hernia repairs [12].

Soothing instrumental music of 60-80 Beats per minute [11] coincides with normal range of heart rate.Patient tends to lower down all the increased vital parameters to normal range as per rate and rhythm of the music; without conscious efforts. Study believes that Instrumental music avoids any bias which could have hampered the results due to lyrical and language barriers.

Mount and Munro studied and concluded that, music intervention is the controlled use of music and its influence on human being: aid in physiological, psychological and emotional integration during treatment of diseases.

Article in MNHPC in 2015 on Dyspnoea Anxiety and Music coated following Dyspnoea anxiety cycle.
This cycle says that because of longer hospital stay, patients suffer from anxiety leading to increased sympathetic response, HR, RR. It further leads to increased $\mathrm{O} 2$ demands and respiratory drive which leads to more energy expenditure and dependency level responsible for anxious behavior.

So effectively reversing this cycle, in the present study patients Showed significant response to music. With $P$ values $(0.00,0.001,0.012,0.00$ and 0.00 ) for PR, SBP, DBP, RR and STAI respectively. Mean HR, RR and STAl showed significant change though mean BP stayed the same.

\section{CONCLUSION}

Music intervention helped in reduction of physiological parameters (respiratory rate, heart rate, Blood pressure) and anxiety in patients with COPD.

Clinical Implications: Music is a non-pharmacological, non-invasive, easy to practice, safe and inexpensive. It can be given as supportive physiotherapy treatment at any time without much prior preparation and without any adverse effect.

\section{ABBREVIATIONS}

COPD - Chronic Obstructive Pulmonary Disease MMRC - Modified Medical Research Council

RR - Respiratory Rate

PR - Pulse Rate

SBP - Systolic Blood Pressure

DBP - Diastolic Blood Pressure

STAI - State Trait Anxiety Inventory

DALYS - Disability Adjusted Life Years

BP - Blood Pressure

\section{ACKNOWLEDGEMENTS}

The Authors wish to thank the management and ethical committee for granting the permission to carry out this project. This opportunity is taken to thank to my family and all the participants who helped make my thesis a reality

\section{Conflicts of interest: None}

\section{REFERENCES}

[1]. World Health Organisation. Global burden of disease estimates.2001 $\{2005,10$ September] Mathers C, Fat DM, Boerma JT. The global burden of disease: 2004 update. World Health Organization; 2008. 
[2]. Chan-Yeung M, Ait-Khaled N, White N, Ip MS, Tan WC. The burden and impact of COPD in Asia and Africa [State of the Art]. The International Journal of Tuberculosis and Lung Disease. 2004 Jan 1;8(1):2-14.

[3]. Bradshaw D, Groenewald P, Laubscher R, Nannan N, Nojilana B, Norman R, Pieterse D, Schneider M, Bourne DE, Timæus IM, Dorrington R. Initial burden of disease estimates for South Africa, 2000. South African Medical Journal. 2003;93(9):682-688.

[4]. Sujit K. Chaudhuris. Concise Medical Physiology. Volume 3. 3rd Edition. edited by Mita Sen M.B.B.S. (4):117-120.

[5]. Niraj Ahuja. A Short Textbook of Psychiatry. $4^{\text {th }}$ edition. Jaypee Brothers.1999(8):82

[6]. Siritunga S, Wijewardena K, Ekanayaka R, Mudunkotuwa P. Effect of music on blood pressure, pulse rate and respiratory rate of asymptomatic individuals: A randomized controlled trial. Health. 2013;5(4A):59-64. Doi: 10.4236/health.2013 $.54 \mathrm{~A} 008$

[7]. Suhartini, Kritptacha,C. Complementary care to reduce anxiety in patients with ventilator support. Malaysian Nursing Journal.2009;1(1):16-23.

[8]. Lee D, Henderson A, Shum D. The effect of music on preprocedure anxiety in Hong Kong Chinese day patients. Journal of clinical nursing. $2004 \mathrm{Mar}$ 1;13(3):297-303.
[9]. Quek KF, Low WY, Razack AH, Loh CS, Chua CB. Reliability and validity of the Spielberger State-Trait Anxiety Inventory (STAI) among urological patients: a Malaysian study. The Medical Journal of Malaysia. 2004 Jun;59(2):258-267.

[10]. Sendelbach SE, Halm MA, Doran KA, Miller EH, Gaillard P. Effects of music therapy on physiological and psychological outcomes for patients undergoing cardiac surgery. Journal of cardio-vascular nursing. 2006 May 1;21(3):194-200.

[11]. Singh VP, Rao V, Prem V, Singh VP, Rao V, Prem V, Sahoo RC, Keshav P. Music and progressive muscle relaxation for anxiety in COPD-a randomized controlled pilot study. Chronic resp Disease 2009;(4):209-216.

[12]. Nilsson U, Unosson M, Rawal N. Stress reduction and analgesia in patients exposed to calming music postoperatively: a randomized controlled trial. European journal of anaesthesiology. 2005;22:96102.

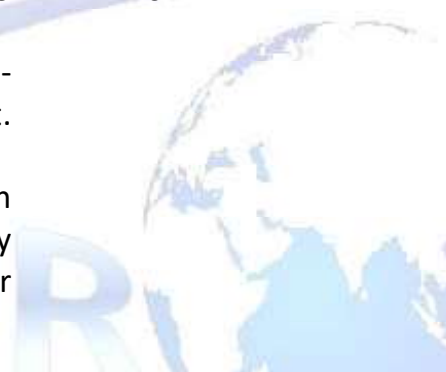

How to cite this article:

Deshmukh Aboli Vivekrao, Nagarwala Raziya, Shyam Ashok, Sancheti Parag.

EFFECT OF MUSIC ON PHYSIOLOGICAL PARAMETERS AND ANXIETY IN

PATIENTS WITH CHRONIC OBSTRUCTIVE PULMONARY DISEASE. Int J

Physiother Res 2018;6(1):2573-2576. DOI: 10.16965/ijpr.2017.152 